\title{
PROBLEMAS NA AVALIAÇÃO DA GERMINAÇÃO DE SEMENTES DE SOJA COM ALTA INCIDÊNCIA DE Phomopsis sp.
}

\section{ADEMIR ASSIS HENNING E JOSÉ DE BARROS FRANÇA NETO ${ }^{1}$}

RESUMO. Com o objetivo de identificar a causa do baixo índice de germinação em laboratório e sugerir medidas que pudessem contornar o problema de descarte de grande número de lotes de sementes de soja produzida na safra 1979/80, no Estado do Paraná, foram realizados vários testes com sementes de diferentes locais e produtores do Estado. Os testes foram os seguintes: germinação a 20 e 300C constantes, análise sanitária, tetrazólio e emergência em casa de vegetação. Tais testes foram realizados com sementes não tratadas (testemunha) e tratadas (fungicidas e hipoclorito de sódio). Constatou-se que o principal fator responsável pela baixa germinação "in vitro" foi o fungo Phomopsis sp., o qual apresentava-se internamente no tegumento das sementes. Houve também, em alguns lotes, alta incidência de Fusarium spp. e Cercospora kikuchii. Nesses lotes, houve resposta ao tratamento das sementes com fungicidas em laboratório e os resultados aí obtidos se equiparam aqueles de emergência em casa de vegetação, onde as condições eram favoráveis à rápida germinação e desfavoráveis ao desenvolvimento do fungo. Em lotes que não responderam ao tratamento de semente, constatou-se, através de teste de tetrazólio, que o problema era causado pela ação de um ou mais dos seguintes fatores: danos mecânicos, deterioração por umidade e danos causados por percevejos. Pelos resultados obtidos, sugeriu-se que, ao invés do teste de germinação em papel toalha, fosse feita a emergência em areia ou, na impossibilidade desta, fosse tratada a amostra com fungicida adequado antes da realização do teste de germinação.

Termos para indexação: fungicidas, corante, germinação, sementes infectadas, Phomopsis, danos mecânicos, emergência em areia, tratamento de sementes.

\section{EVALUATION PROBLEMS IN THE GERMINATION OF SOYBEAN SEED LOTS WITH HIGH INCIDENCE OF Phomopsis sp.}

ABSTRACT. The objective of this work was to find out the cause of the low level of germination in laboratory, and to suggest measures that could avoid the discard

1

Pesquisador da EMBRAPA - Centro Nacional de Pesquisa de Soja. Cx. Postal 1061. 86.100 , Londrina, PR. 
of a great number of soybean seed lots produced during the 1979/80 growing season in the State of Parana. Several tests were carried out with seed from different places and seed producers of that State. The tests were the following: standard germination test at constant temperatures of 25 and $30{ }^{\circ} \mathrm{C}$; seed health test; tetrazolium test; and emergence in greenhouse. These tests were made with untreated seed (check) and treated seed (fungicide and sodium hypochlorite). The main factor responsible for the low germination "in vitro" was the fungus Phomopsis sp., which occured internally in the seed coat. In some seed lots there was a high incidence of Fusarium spp. and Cercospora kikuchii. In these lots, there was response to the fungicidal seed treatment in the laboratory and the results obtained were similar to those in the greenhouse, where conditions were favorable for a rapid germination and unfavorable for the development of the fungus. In those lots in which the germination was not improved by the seed treatment, it was found, through the tetrazolium test, that the problem was caused by the action of one or more of the following factors: mechanical damage, moisture deterioration and stink bug injury. Based on the results, in was suggested that, instead of the standard germination test with paper towels, the sand emergence test should be made, or a treatment of the seed sample with and adequate fungicide before running the standard germination test.

Index terms: fungicides, pigment, germination, infected seed, Phomopsis, mechanical damage, sand emergence, seed treatment.

\section{INTRODUÇÃO}

É comum a ocorrência de condições climáticas desfavoráveis durante a fase final de maturação da soja. Freqüentemente, o excesso de chuvas, associado a altas temperaturas, ocasiona verdadeiro desastre na produção de sementes, as quais, além do processo de deterioração fisiológica devido à flutuação do teor de umidade, apresentam altos índices de infecção, principalmente causada por fungos.

Dentre os microrganismos destaca-se a presença do fungo Phomopsis sp., responsável pela deterioração da qualidade das sementes. Freqüentemente, este microrganismo causa o apodrecimento das sementes, principalmente durante os testes de germinação "in vitro", devido às condições em que geralmente estes testes são conduzidos. A temperatura utilizada de $25^{\circ} \mathrm{C}$ é a temperatura ótima para o desenvolvimento do Phomopsis, o qual pode interferir nos resultados, tornando a utilização do teste de germinação inviável quando as sementes apresentam elevados índices de infecção. 
A semente pode estar contaminada de duas maneiras: internamente e externamente. Internamente, esse e muitos outros microrganismos podem ocorrer na forma de micélio dormente, sendo encontrados no tegumento, cotilédones e mesmo no embrião, dependendo do patógeno envolvido. Externamente, os esporos e os micélios dos fungos podem permanecer aderidos ao tegumento. Isto acontece principalmente durante os processos de colheita e trilha, em que as sementes tomam contacto com hastes e vagens repletas de picnídios e demais estruturas dos fungos. Tal processo possibilita o "espalhamento" das estruturas (esporos e micélios) sobre as sementes, contaminando-as.

Durante a safra 1979/80, as cultivares que não escaparam às chuvas sofreram intensamente os efeitos da deterioração no campo, além de estarem altamente infectadas e/ou infestadas com fungos.

Foi muito frequente a reclamação por parte dos produtores de sementes, os quais estavam encontrando dificuldades em obter o índice de $80 \%$ de germinação nos testes de laboratório. A maioria deles relatou a ocorrência de "um fungo branco", o qual causava o apodrecimento intenso das sementes no germinador.

Amostras trazidas ao Centro Nacional de Pesquisa de Soja CNPSo mostraram que as sementes estavam com quase 100\% de Phomopsis sp., sendo observada, também, a presença de Colletotrichum dematium (Pres. ex Fr.) Grove var. truncata (Schw.) Arx. e Fusarium spp., em menor intensidade.

Foi relatado o fato de que a emergência a campo, bem como o resultado no teste de envelhecimento precoce $\left(40^{\circ} \mathrm{C}\right)$, eram superiores à porcentagem de germinação obtida pelo teste padrão $\left(25^{\circ} \mathrm{C}\right.$ ou $\left.20-30^{\circ} \mathrm{C}\right)$.

Segundo relatos de diversos produtores, este problema estaria generalizado em algumas regiões dos Estados do Paraná, sul de Minas Gerais e São Paulo, e, caso não fosse encontrada uma solução, que permitisse avaliar o potencial germinativo do lote (sem a interferência do fungo), grande número de lotes de semente com alto índice de pureza varietal seria descartado. Se tal fato houvesse sido concretizado, os lotes com menor pureza varietal, mas que não apresentassem o problema da germinação, poderiam ter sido aprovados para serem utilizados como semente fiscalizada. Além disso, poderia ter havido necessidade de importar sementes de outros Estados, cujos padrões eram inferiores ao do Estado do Paraná.

Para explicar o fato da emėrgência a campo e o resultado do teste de envelhecimento precoce serem superiores à germinação do teste padrão várias hipóteses foram levantadas:

1. No campo: a. o fungo não encontra as mesmas condições ideais para o seu desenvolvimento $\left(25^{\circ} \mathrm{C}\right.$ e alta umidade), além da presença de possíveis organismos antagônicos; b. existe também a possibilidade de escape por parte das plântulas, que 
ao emergirem, deixam o tegumento contaminado no solo, ficando os cotilédones livres. Já no teste padrão de germinação, o tegumento fica aderido aos cotilédones, dando condições para que o fungo se desenvolva, causando o apodrecimento dos mesmos.

2. No laboratório: a. a temperatura de $40^{\circ} \mathrm{C}$ utilizada no teste de envelhecimento precoce é desfavorável ao desenvolvimento do fungo; b. as sementes poderiam estar altamente contaminadas, mas apenas superficialmente, e esta hipótese poderia ser confirmada pelo tratamento de desinfestação superficial com o hipoclorito de sódio, que seria suficiente para elevar a germinação nos germinadores.

Assim, foram conduzidos diversos experimentos de laboratório e casa de vegetação, buscando-se determinar qual a situação real das sementes, e apontar possíveis soluções para o problema.

\section{MATERIAL E MÉTODOS}

As sementes utilizadas nessa pesquisa foram enviadas ao CNPSo, por produtores de Londrina, Cornélio Procópio e Ponta Grossa. Foram recebidas ao todo 20 amostras, sendo dez da cultivar Paraná (PR-21 a PR-30) produzidas na região sul de Minas Gerais, quatro de 'Andrews', três de 'Viçoja' e uma 'Paraná', produzidas em Cornélio Procópio; uma amostra 'Davis' produzida em Londrina; e finalmente uma amostra de 'Bossier', produzida em Ponta Grossa, PR.

No laboratório estas amostras, exceto a de 'Davis', foram divididas em três sub-amostras, sendo uma tratada com captan (Captan 75SP), outra com thiabendazol (Tecto 10-S) e a terceira sem tratamento, que serviu de testemunha. A dose empregada foi $2 \mathrm{~g}$ do produto comercial $/ \mathrm{kg}$ de semente. Para os ensaios de laboratório (Blotter test e germinação), as sub-amostras do tratamento testemunha foram novamente divididas em duas porções. Uma dessas porções foi desinfestada superficialmente com uma solução a $1,3 \%$ de hipoclorito de sódio, ou $25 \%$ do produto comercial Q-Boa, por um minuto e, posteriormente, enxaguada com água destilada autoclavada. A outra porção das sub-amostras testemunhas não sofreu nenhum tratamento. Com isso, buscou-se determinar se o fungo estava superficialmente aderido ao tegumento das sementes ou localizado internamente.

As sementes da cultivar Davis foram divididas em doze sub-amostras, de $700 \mathrm{~g}$ cada, que foram tratadas com os seguintes fungicidas e respectivas doses do produto comercial por amostra: 1 . chloroneb (Demosan $65 \mathrm{~W}$ ), 2,1 g; 2. thiabendazol (Tecto 10-S), 1,4 g; 3. thiram (Rhodiauran) 2,1 g; 4. tiofanato metílico + thiram (Cercoram $80 \mathrm{PM}$ ), 2,45 g; 5. carboxin (Vitavax 75 PM), 2,1 g; 6. PCNB (Brassicol 75 PS), 
2,1 g; 7. captan (Captan 75 SP), 1,4 g; 8. captafol + PCNB (Folseed), 2,8 g; 9. thiram + Rhizobium + Mo (Triple Noctin ${ }^{\mathrm{R}}$ ), 3,15 ml; 10. TCMTB (Busan 30E), $3,15 \mathrm{ml} ; 11$. testemunha; 12 . Testemunha esterilizada com Na0C1 a $1,3 \%$.

\section{Experimentos}

1. Blotter Test: as sementes de todos os tratamentos foram colocadas em Gerbox (caixas plásticas de $11 \mathrm{~cm}$ x $11 \mathrm{~cm} \mathrm{x} 3,5 \mathrm{~cm}$ ) devidamente esterilizadas com hipoclorito de sódio a $25 \%$ do produto comercial Q-Boa, contendo' no seu interior quatro folhas de papel filtro umidecidas com água destilada e autoclavada. Foram utilizadas dez gerbox por amostra, cada gerbox com 20 sementes. Após o período de incubação de sete dias, a $25^{\circ} \mathrm{C}$, foi efetuada a contagem das sementes infectadas e os resultados expressos em percentagem.

2. Testes de Germinação: para estes testes, utilizaram-se quatro repetições de

50 sementes cada, colocadas em papel toalha "Germitest", utilizando-se as temperaturas constantes de $25^{\circ} \mathrm{C}$ e $30^{\circ} \mathrm{C}$, por cinco dias.

3. Teste de Tetrazólio: somente as amostras testemunhas, sem qualquer tratamento, foram testadas para se determinar potencial de germinação, nível de vigor, índice de danos mecânicos, deterioração por umidade e ataque de percevejos. Foram utilizadas duas repetições de 50 sementes por amostra, precondicionadas em papel toalha "Germitest", umidecido por 16 horas, sendo posteriormente colocadas numa solução $0,05 \%$ de sal de tetrazólio, por três horas, em câmara a $35^{\circ} \mathrm{C}$.

4. Emergência em casa de vegetação: para se avaliar a emergência das sementes com e sem os tratamentos fungicidas, instalou-se um experimento em blocos completos casualizados com três repetições de 100 sementes por tratamento. As sementes foram semeadas em caixas retangulares de folha galvanizada, com solo não esterilizado, sendo distribuídas ao acaso. Estas caixas foram mantidas úmidas e a temperatura mantida ao redor de $25^{\circ} \mathrm{C}$. A contagem da emergência foi efetuada dez dias após a semeadura.

\section{RESULTADOS E DISCUSSÃO}

Conforme pode-se observar na Tabela 1, todas as dez amostras de soja 'Paraná' apresentavam alta incidência de sementes infectadas com Phomopsis sp. Observou-se também um razoável grau de infecção de Cercospora kikuchii $( \pm 12 \%)$, enquanto que a presença de Colletotrichum dematium var. truncata, Fusarium spp. e Alternaria spp. foi mínima. 
Os resultados da análise sanitária demonstraram que os microrganismos em questão estavam localizados internamente na semente e não aderidos externamente, como o suposto anteriormente. Este fato foi comprovado porque a desinfestação superficial com hipoclorito de sódio praticamente não alterou a freqüencia de incidência dos patógenos em questão.

Sabe-se de literatura que o principal patógeno das sementes de soja, Phomopsis sp., preferentemente coloniza os tecidos do tegumento da semente e ocasionalmente node infectar as primeiras camadas da epiderme dos cotilédones (Hepperly « Sinclair 1978, Rodrigues Marcano \& Sinclair 1978). Já o Colletotrichum, segundo Scheneider et al. (1974), é encontrado somente nas primeiras camadas do tegumento, nunca ocorrendo nas suas camadas mais profundas e nos cotilédones ou no embrião. Por outro lado, o micélio de $C$. kikuchii é encontrado abundante e igualmente nas camadas do tegumento, com maior freqüência na região do hilo. Pode, também segundo Ilyas et al. (1975), ser encontrado nos tecidos cotiledonares, como epiderme e parênquima.

Neste estudo, o tratamento das sementes com thiabendazol e captan elevou acentuadamente a porcentagem de sementes germinadas sadias, sendo que o thiabendazol proporcionou germinação superior a $90 \%$, erradicando, praticamente, todos os principais patógenos de soja (Phomopsis, Colletotrichum, Fusarium e $C$. kikuchii).

Os resultados do ıeste padrão de germinação estão também ilustrados na Tabela 1. Tornou-se evidente a resposta dos tratamentos fúngicos sobre a germinação, mostrando um aumento médio superior a $20 \%$ em relação à etstemunha. Observou-se nitidamente uma queda na porcentagem de plântulas infectadas para as amostras tratadas e um ligeiro aumento na porcentagem de anormais. Verificouse que os resultados de emergência em casa de vegetação, também resumidos na Tabela 1, são consistentemente superiores aos percentuais de germinação obtidos pelo teste de laboratório para as testemunhas. Isto demonstra claramente que, devido à infecção das sementes pelos microrganismos mencionados, o teste padrão de germinação em rolos de papel não estava avaliando corretamente o potencial de viabilidade das sementes.

A emergência em casa de vegetação não apresentou diferença entre a testemunha e as amostras tratadas com fungicidas. Não obstante, tais valores não diferiram daqueles observados em laboratório, quando as sementes foram tratadas com thiabendazol ou captan.

Partindo-se da premissa de que o fungo Phomopsis sp. estava interferindo com os resultados do teste de germinação a $25{ }^{\circ} \mathrm{C}$, procurou-se uma solução alternativa. Utilizou-se a temperatura constante de $30^{\circ} \mathrm{C}$, como prescrito pelas "Regras 
Tabela 1. Resultados das análises efetuadas em dez lotes de sementes de soja da cultivar Paraná, produzıda em Minas Gerais na safra 1979/80. EMBRAPA/CNPSo. Londrina, PR. 1980.

\begin{tabular}{|c|c|c|c|c|c|c|c|c|c|}
\hline \multirow[b]{2}{*}{ Amostra } & \multirow[b]{2}{*}{ Tratamento } & \multirow{2}{*}{$\begin{array}{l}\text { Phomopsis sp. } \\
\%\end{array}$} & \multicolumn{3}{|c|}{ Germinaçâo (\%) } & \multirow{2}{*}{$\begin{array}{c}\text { Emerg. casa } \\
\text { de veget. } \\
(\%)\end{array}$} & \multicolumn{3}{|c|}{$\mathrm{Tz}-$ danos $(6-8)$} \\
\hline & & & $25^{\circ} \mathrm{C}$ & $30^{\circ} \mathrm{C}$ & $\mathrm{Tz}$ & & Mec. & Umi. & Perc. \\
\hline \multirow[t]{4}{*}{ PR-21 } & Captan & 1,0 & 92 & - & - & 87 & . & - & - \\
\hline & Thiabendazol & 0,0 & 96 & - & - & 93 & - & - & - \\
\hline & Testemunha & 45,0 & 75 & 91 & 91 & 95 & 07 & 04 & 00 \\
\hline & Test. NaOCl & 46,0 & 79 & - & - & - & - & - & $\cdot$ \\
\hline \multirow[t]{4}{*}{ PR-22 } & Captan & 0,5 & 95 & - & - & 96 & - & - & - \\
\hline & Thiabendazol & 0,0 & 97 & - & - & 93 & - & - & - \\
\hline & Testemunha & 38,5 & 77 & 92 & 95 & 97 & 05 & 91 & 00 \\
\hline & Test. $\mathrm{NaOCl}$ & 44,0 & 83 & - & - & - & - & - & - \\
\hline \multirow[t]{4}{*}{ PR-23 } & Captan & 15,0 & 85 & - & - & 93 & . & - & . \\
\hline & Thiabendazol & 0,0 & 95 & - & . & 92 & . & - & . \\
\hline & Testemunha & 62,0 & 63 & 87 & 86 & 90 & 14 & 10 & 00 \\
\hline & Test. $\mathrm{NaOCl}$ & 65,0 & 70 & - & - & - & - & $\cdot$ & - \\
\hline \multirow[t]{4}{*}{ PR-24 } & Captan & 8,0 & 82 & - & - & 91 & - & $\because$ & - \\
\hline & Thiabendazol & 0,0 & 97 & - & - & 84 & - & - & - \\
\hline & Testemunha & 58,5 & 62 & 87 & 86 & 90 & 12 & 05 & 01 \\
\hline & Test. $\mathrm{NaOCQ}$ & 56,5 & 70 & - & - & $\cdot$ & - & - & $\cdot$ \\
\hline \multirow[t]{4}{*}{ PR-25 } & Captan & 3,5 & 87 & - & - & 96 & - & - & - \\
\hline & Thiabendazol & 0,0 & 97 & - & - & 85 & - & - & - \\
\hline & Testemunha & 49,5 & 82 & 93 & 92 & 96 & 08 & 05 & 00 \\
\hline & Test. $\mathrm{NaOCQ}$ & 48,5 & 81 & - & $\cdot$ & - & . & - & - \\
\hline \multirow[t]{4}{*}{ PR.26 } & Captan & 3,0 & 85 & - & - & 91 & - & - & - \\
\hline & Thiabendazol & 0,0 & 95 & - & - & 94 & - & . & . \\
\hline & Testemunha & 64,0 & 79 & 85 & 96 & 89 & 04 & 02 & 01 \\
\hline & Test. $\mathrm{NaOCl}$ & 54,0 & 68 & - & - & - & - & - & $\cdot$ \\
\hline \multirow[t]{4}{*}{ PR-27 } & Captan & 10,0 & 87 & - & - & 89 & . & - & . \\
\hline & Thiabendazol & 0,0 & 94 & - & - & 92 & . & - & - \\
\hline & Testemunha & 65,0 & 69 & 88 & 91 & 88 & 08 & 02 & 01 \\
\hline & Test, $\mathrm{NaOCl}$ & 61,5 & 73 & - & - & - & - & - & - \\
\hline \multirow[t]{4}{*}{ PR-28 } & Captan & 6.5 & 87 & - & . & 92 & - & . & . \\
\hline & Thiabendazol & 0,0 & 94 & - & - & 93 & - & - & - \\
\hline & Testemunha & 52,0 & 70 & 89 & 85 & 92 & 14 & 08 & 00 \\
\hline & Test. $\mathrm{NaOCl}$ & 62.5 & 72 & - & - & - & . & - & - \\
\hline \multirow[t]{4}{*}{ PR-29 } & Captan & 7,5 & 83 & - & - & 94 & - & - & - \\
\hline & Thiabendazol & 0.0 & 93 & - & - & 92 & - & . & . \\
\hline & Testemunha & 53,5 & 71 & 84 & 87 & 91 & 12 & 08 & 00 \\
\hline & Test. $\mathrm{NaOCl}$ & 46,0 & 75 & - & - & . & - & $\cdot$ & - \\
\hline \multirow[t]{4}{*}{ PR-30 } & Captan & 17,5 & 75 & - & - & 93 & - & - & - \\
\hline & Thiabendazol & 0,0 & 94 & - & - & 88 & - & - & - \\
\hline & Testemunha & 73,0 & 53 & 82 & 87 & 91 & 11 & 10 & 00 \\
\hline & Test. $\mathrm{NaOC \ell}$ & 66,0 & 67 & - & - & - & - & - & $\therefore$ \\
\hline
\end{tabular}


para Análise de Sementes", buscando-se evitar a temperatura ideal para o crescimento do referido microrganismo.

Conforme se esperava, tal condição elevou a porcentagem de germinação de todos os lotes a níveis superiores a $80 \%$, atingindo em alguns casos, mais de $90 \%$ (Tabela 1).

O teste de tetrazólio, cujos resultados são resumidos também na Tabela 1, revelou bons índices de vigor e germinação potencial. Nota-se, de maneira geral, que além dos patógenos de sementes, não detectados por este teste, a interação de danos mecânicos e deterioração por umidade foi responsável pela ligeira queda na viabilidade das sementes.

O nível 6 a 8 do teste de tetrazólio expressa a porcentagem de sementes não germináveis. Para se determinar a causa real da queda de germinação, foram anotados os porcentuais de sementes não germináveis com sinais de danos mecânicos, deterioração por umidade e ataque de percevejo. Para facilitar a compreensão e a interpretação desses resultados, menciona-se como exemplo a amostra número PR-24: sua germinaçâo potencial foi de $86 \%$, o que significa que nesta amostra temse $14 \%$ de sementes não germináveis, ou seja, $100 \%$ menos $86 \%$. Então, para tal amostra tem-se $14 \%$ de sementes que não germinaram devido à ação ou interação dos fatores mencionados na seguinte proporção: $12 \%$ devido a danos mecânicos, $5 \%$ a deterioração por umidade e $1 \%$ a ataque de percevejo.

$\mathrm{Na}$ Tabela 2 estão resumidos os resultados das análises efetuadas nas sementes das oito amostras oriundas de Cornélio Procópio, PR.

Dentre as oito amostras recebidas, as três de 'Viçoja' apresentaram os maiores índices de Phomopsis sp. (acima de 40\%). Observou-se também uma incidência considerável de Fusarium spp. em todos os oito lotes. As amostras da cultivar Andrews tinham ocorrência média de Phomopsis spp. $( \pm 16 \%)$ a alta de C. kikuchii (em torno de $30 \%)$.

Mais uma vez os tratamentos com fungicidas elevaram a porcentagem de sementes germinadas sadias para cerca de $90 \%$, destacando-se o thiabendazol como 0 fungicida mais eficiente.

Os tratamentos com fungicidas elevaram a germinação da maioria dos lotes, com excessão de três deles, que apresentaram bons índices iniciais, ou seja, acima do padrão mínimo de $80 \%$.

Quanto à emergência em casa de vegetação, notou-se novamente a semelhança dos resultados da germinação padrão das amostras tratadas com a emergência das testemunhas.

A germinação a $30^{\circ} \mathrm{C}$ para estas amostras, não apresentou resultados consistentes como os obtidos nas amostras de 'Paraná', citados anteriormente, evidencian- 
Tabela 2. Resultados das análises efetuadas em oito lotes de sementes de soja de diversas cultivares, produzidas na região de Cornélio Procópio, PR, na safra 1979/80. EMBRAPA/CNPSo. Londrina, PR. 1980.

\begin{tabular}{|c|c|c|c|c|c|c|c|c|c|c|c|}
\hline \multirow[t]{2}{*}{ Amostra } & \multirow[t]{2}{*}{ Tratamento } & \multicolumn{3}{|c|}{ Blotter test } & \multicolumn{3}{|c|}{ Germinaçâo (\%) } & \multirow{2}{*}{$\begin{array}{c}\text { Emerg. casa } \\
\text { de veget. } \\
(\%)\end{array}$} & \multicolumn{3}{|c|}{$\mathrm{Tz}-\operatorname{danos}(6-8)$} \\
\hline & & $\mathrm{Ph}^{1}$ & Fu. $^{2}$ & $\mathrm{Ck}^{3}$ & $25^{\circ} \mathrm{C}$ & $30^{\circ} \mathrm{C}$ & $\mathrm{Tz}$ & & Mec. & Umi. & Perc. \\
\hline \multirow{4}{*}{$\begin{array}{c}\text { Viçoja } \\
1\end{array}$} & Captan & 5,5 & 2,5 & 0,0 & 86 & - & - & 95 & - & - & - \\
\hline & Thiabendazol & 0,0 & 0,0 & 0,0 & 92 & - & - & 93 & - & - & - \\
\hline & Testemunha & 40,5 & 11,0 & 5,5 & 75 & 73 & 95 & 89 & 04 & 01 & 03 \\
\hline & Test. $\mathrm{NaOCl}$ & 46,0 & 16,0 & 0,0 & 66 & - & - & - & - & - & - \\
\hline \multirow{4}{*}{$\begin{array}{c}\text { Viçoja } \\
2\end{array}$} & Captan & 6,0 & 0,5 & 0,0 & 94 & - & - & 93 & - & - & - \\
\hline & Thiahendazol & 0,0 & 1,5 & 0,0 & 93 & - & - & 97 & - & - & - \\
\hline & Testemunha & 52,0 & 21,5 & 1,5 & 78 & 85 & 90 & 90 & 07 & 06 & 05 \\
\hline & Test. NaOCl & 41,5 & 13,0 & 2,0 & 72 & - & - & - & - & - & - \\
\hline \multirow{4}{*}{$\begin{array}{c}\text { Viçoja } \\
3\end{array}$} & Captan & 11,5 & 3,0 & 0,0 & 86 & - & - & 92 & - & - & - \\
\hline & Thiabendazol & 0,0 & 0,5 & 0,0 & 94 & - & - & 93 & - & - & - \\
\hline & Testemunha & 48,0 & 25,5 & 6,0 & 72 & 66 & 91 & 85 & 00 & 04 & 07 \\
\hline & Test. $\mathrm{NaOCl}$ & 52,5 & 15,0 & 4,0 & 58 & - & - & - & - & - & - \\
\hline \multirow{4}{*}{$\begin{array}{c}\text { Paraná } \\
4\end{array}$} & Captan & 3,5 & 0,5 & 1,0 & 89 & - & - & 96 & - & - & - \\
\hline & Thiabendazol & 0,0 & 0,5 & 0,0 & 92 & - & - & 97 & - & - & - \\
\hline & Testemunha & 12,0 & 6,5 & 3,0 & 92 & 80 & 87 & 91 & 06 & 08 & 03 \\
\hline & Test. $\mathrm{NaOCl}$ & 16,5 & 7,5 & 1,5 & 90 & - & - & - & - & - & - \\
\hline \multirow{4}{*}{$\begin{array}{l}\text { Andrews } \\
5\end{array}$} & Captan & 1,0 & 0,0 & 0,5 & 92 & - & - & 94 & - & - & - \\
\hline & Thiabendazol & 0,0 & 0,0 & 0,0 & 91 & - & - & 97 & - & - & - \\
\hline & Testemunha & 15,0 & 11,0 & 24,0 & 88 & 66 & 83 & 95 & 17 & 03 & 06 \\
\hline & Test. NaOCl & 11,0 & 7,0 & 13,0 & 87 & - & - & - & - & - & - \\
\hline \multirow{4}{*}{$\begin{array}{c}\text { Andrews } \\
6\end{array}$} & Captan & 1,5 & 0,5 & 0,5 & 80 & - & - & 93 & - & - & - \\
\hline & Thiabendazol & 0,0 & 0,0 & 0,0 & 86 & - & - & 94 & - & - & - \\
\hline & Testemunha & 15,5 & 17,5 & 25,5 & 85 & 76 & 80 & 90 & 07 & 04 & 15 \\
\hline & Test. $\mathrm{NaOC} \ell$ & 8,0 & 7,0 & 18,0 & 76 & - & - & - & - & - & - \\
\hline \multirow{4}{*}{$\begin{array}{c}\text { Andrews } \\
7\end{array}$} & Captan & 2,5 & 0,0 & 0,5 & 96 & - & - & 99 & - & - & - \\
\hline & Thiabendazol & 0,0 & 0,5 & 0,0 & 90 & - & - & 98 & - & - & - \\
\hline & Testemunho & 16,5 & 9,5 & 32,0 & 83 & 90 & 91 & 99 & 08 & 00 & 01 \\
\hline & Test. $\mathrm{NaOCl}$ & 14,0 & 10,0 & 26,0 & 83 & - & - & - & - & - & - \\
\hline \multirow{4}{*}{$\begin{array}{c}\text { Andrews } \\
8\end{array}$} & Captan & 3,5 & 3,5 & 0,0 & 88 & - & - & 95 & - & - & - \\
\hline & Thiabendazol & 0,0 & 0,0 & 0,0 & 87. & - & - & 98 & - & - & - \\
\hline & Testemunha & 21,5 & 12,0 & 31,0 & 74 & 63 & 86 & 92 & 10 & 02 & 08 \\
\hline & Test. $\mathrm{NaOCl}$ & 12,0 & 6,5 & 24,0 & 78 & - & - & - & - & - & - \\
\hline
\end{tabular}

${ }_{2}^{1} \mathrm{Ph} .=$ Phomopsis sp.

${ }_{3}^{2} \mathrm{Fu} .=$ Fusarium spp.

$\mathrm{Sk}=$ Cercospora kikuchii 
do outros fatores, além de Phomopsis sp., responsáveis pela queda na viabilidade das sementes. Possivelmente a presença de Fusarium spp. e Colletotrichum, associada a outros problemas, como danos mecânicos, deterioração por umidade e ataque de percevejos interferiram com os resultados deste teste.

Dos três lotes que não responderam aos tratamentos fúngicos no teste de germinação, o lote nọ 4 da cultivar Paraná, apesar de já ter um bom índice de germinação, apresentou o maior nível (6-8) de deterioração por umidade, conforme a Tabela 2. Os outros dois lotes, Andrews 5 e 6, apresentaram os maiores índices (6 - 8) de danos mecânicos e ataque de percevejos, respectivamente. Tal situação demonstra que o tratamento de sementes não trará grandes benefícios quando estas apresentam elevados índices de danos mecânicos, deterioração por umidade e danos por percevejos, conforme evidenciados pelo nível (6 - 8) do teste de tetrazólio.

Os resultados das análises das sementes da cultivar Davis, produzidas em Londrina, PR, encontram-se resumidos na Tabela 3. Conforme se pode observar, o índice de sementes infectadas foi bastante baixo, mas todos os dez fungicidas utilizados reduziram praticamente a zero a incidência de Phomopsis sp.

Os valores do teste padrão de germinação mostram uma melhora com os tratamentos fúngicos, com excessão do fungicida Busan $30 \mathrm{E}$ (TCMTB), o qual por erro de dosagem, se mostrou bastante tóxico. Os fungicidas que melhor se comportaram foram, em ordem decrescente: thiabendazol (Tecto 10-S), carboxin (Vitavax 75 PM), captan (Captan 75 SP) e thiram (Rhodiauran).

A emergência em casa de vegetação foi superior a $80 \%$ para todos tratamentos inclusive a testemunha (84\%) exceto o TCMTB (Busan $30 \mathrm{E}$ ) que apresentou toxidez devido ao erro de dosagem.

Vale ressaltar mais uma vez que o nível considerado baixo de Phomopsis sp. (11\%), constatado no teste de sanidade (Blotter), foi suficiente para ocasionar problemas na avaliação de germinação deste lote.

A germinação a $300^{\circ}$ foi ligeiramente inferior à observada a $25{ }^{\circ} \mathrm{C}$, apesar de a percentagem de sementes infectadas ter decrescido. Tal fato deve-se à alta incidência de sementes com sinais de danos mecânicos e deterioração por umidade, constatada no nível $(6-8)$ do teste de tetrazólio.

Finalmente, na Tabela 4, estão resumidos os resultados das análises realizadas nas sementes de 'Bossier', produzidas em Ponta Grossa, PR.

Dentre os fungos isolados das sementes, Phomopsis sp. contribuiu com $53,12 \%$, Fusarium spp. e C. kikuchii apresentaram 3,9\% e 7,75\%, respectivamente.

O tratamento com hipoclorito de sódio (desinfestação superficial) reduziu acentuadamente estes índices, todavia acredita-se ter ocorrido a penetração do produto por rachaduras do tegumento, que ocasionou a erradicação dos patógenos 
Tabela 3. Resultados das análises efetuadas em sementes de soja da cultivar Davis, produzidas na safra 1979/80, procedentes de cooperativa de Londrina, PR e submetidas a tratamento com diversos fungicidas. EMBRAPA/CNPSo. Londrina, PR. 1980.

\begin{tabular}{|c|c|c|c|c|c|c|c|c|c|}
\hline \multirow[t]{2}{*}{ Tratamento } & \multirow[t]{2}{*}{ Dose $/ \mathrm{kg}$} & \multirow{2}{*}{$\begin{array}{l}\text { Blotter test } \\
\text { Phomopsis }\end{array}$} & \multicolumn{3}{|c|}{ Germinação \% } & \multirow{2}{*}{$\begin{array}{l}\text { Emerg. casa } \\
\text { de veget. } \\
(\%)\end{array}$} & \multicolumn{3}{|c|}{$\mathrm{Tz}-\operatorname{Danos}(6-8)$} \\
\hline & & & $25^{\circ} \mathrm{C}$ & $30^{\circ} \mathrm{C}$ & $\mathrm{Tz}$ & & Mec. & Umi. & Perc. \\
\hline Demosan 65 W & $3 \mathrm{~g}$ & 0,0 & 78 & - & - & 82 & - & - & - \\
\hline Tecto $10-\mathrm{S}$ & $2 \mathrm{~g}$ & 0,0 & 84 & - & - & 84 & - & - & - \\
\hline Rhodiauran & $3 \mathrm{~g}$ & 1,0 & 81 & - & - & 85 & - & - & - \\
\hline Cercoran 80PM & $3 \mathrm{~g}$ & 0,0 & 76 & - & - & 84 & - & - & - \\
\hline Vitavax 75 PM & $2 \mathrm{~g}$ & 0,0 & 82 & - & - & 87 & - & - & - \\
\hline Brassicol 75 PS & $3 \mathrm{~g}$ & 0,0 & 78 & - & - & 85 & - & - & - \\
\hline Captan 75 SP & $2 \mathrm{~g}$ & 0,0 & 81 & - & - & 88 & - & - & $\cdot$ \\
\hline Folseed & $4 \mathrm{~g}$ & 0,0 & 80 & - & - & 88 & - & - & - \\
\hline Triple Noctin ${ }^{R}$ & $4,4 \mathrm{ml}$ & 0,0 & 79 & - & - & 81 & - & - & - \\
\hline Busan $30 \mathrm{E}$ & $4,5 \mathrm{ml}$ * & 1,0 & $57 *$ & - & - & 64 & - & - & - \\
\hline Testemunha & - & 11,0 & 72 & 68 & 81 & 84 & 15,0 & 12,0 & 3,0 \\
\hline Test. $\mathrm{NaOCl}$ & - & 6,0 & 77 & - & - & - & - & - & - \\
\hline
\end{tabular}

*Fungicida utilizado com dose $10 \mathrm{x}$ superior a recomendada. 
Tabela 4. Resultado das análises efetuadas em um lote de sementes da cultivar Bossier, produzida na região de Ponta Grossa, PR, na safra 1979/80. EMBRAPA/CNPSo. Londrina, PR. 1980.

\begin{tabular}{|c|c|c|c|c|c|c|c|c|c|c|}
\hline \multirow[t]{2}{*}{ Tratamento } & \multicolumn{3}{|c|}{ Blotter test } & \multicolumn{3}{|c|}{ Germinação \% } & \multirow{2}{*}{$\begin{array}{l}\text { Emerg. casa } \\
\text { de veget. } \\
(\%)\end{array}$} & \multicolumn{3}{|c|}{$\mathrm{Tz}-\operatorname{Danos}(6-8)$} \\
\hline & Ph. $^{1}$ & $\mathrm{Fu}^{2}$ & $\mathrm{Ck}^{3}$ & $25^{\circ} \mathrm{C}$ & $300 \mathrm{C}$ & $\mathrm{Tz}$ & & Mec. & Umi. & Perc. \\
\hline Captan & 1,12 & 1,40 & 0,0 & 70 & - & - & 78 & - & - & - \\
\hline Thiabendazol & 0,12 & 0,04 & 0,0 & 77 & - & - & 79 & - & - & - \\
\hline Testemunha & 53,12 & 3,90 & 7,75 & 68 & 71 & 73 & 76 & 26 & 09 & 04 \\
\hline Test. NaOCl & 30,25 & 1,50 & 3,40 & 69 & - & - & - & - & - & - \\
\hline
\end{tabular}

\footnotetext{
${ }_{1} \mathrm{Ph} .=$ Phomopsis sp.

2 Fu. = Fusarium spp.

$3 \mathrm{Ck} .=$ Cercospora kikuchii
} 
localizados internamente nas sementes. Isto foi demonstrado pelo teste de tetrazólio (Tabela 4) que mostrou elevadíssimos índices de danos mecânicos constatados nos níveis (6 - 8).

Os resultados dos testes de germinação, tanto a $25^{\circ} \mathrm{C}$ como a $30^{\circ} \mathrm{C}$, e de emergência em casa de vegetação demonstraram neste caso, que os fungicidas não conseguiram elevar estes índices a $80 \%$, apesar do alto índice de Phomopsis sp. $(53,12 \%)$. Isto demonstra que o tratamento sistemático dos lotes de sementes, tomando-se como base apenas os dados de germinação e/ou análise sanitária, pode vir a ser ineficiente.

\section{CONCLUSÕES E SUGESTÕES}

A análise dos resultados obtidos nos diversos testes efetuados com sementes de diferentes origens, permitiu ao CNPSo sugerir medidas visando impedir o descarte de grande parte dos lotes de sementes produzidas, principalmente nas regiões norte e centro sul do Paraná.

Sugeriu-se que as amostras que não atingissem o padrão mínimo de germinação de $80 \%$ e em que fosse notada a presença de fungo nos rolos de papel substrato, fossem submetidas ao teste de germinação em areia, conforme as Regras para Análise de Sementes. Caso o problema persistisse, tal lote não deveria ser aprovado.

A outra possibilidade seria, caso o laboratório não possuisse infra-estrutura para a realização do teste em areia, que efetuasse o tratamento da amostra com fungicida, porém tal prática não é permitida, de acordo com as Regras para Análise de Sementes. A aprovação do lote ficaria ainda na dependência do "índice de melhoria" observado por ocasião da germinação da amostra tratada, a qual deveria propiciar uma boa margem de segurança acima dos $80 \%$ requeridos. Isto porque ocorre o processo natural de deterioração da semente durante a armazenagem, ocasionando uma queda no potencial de germinação do lote, por ocasião do plantio.

Mesmo que um lote fosse aprovado como semente, não se recomendou o tratamento do lote antes ou durante a armazenagem, devido a uma séria de inconvenientes dentre os quais destacam-se:

1. O perigo da comercialização, para a indústria, de lotes tratados, o que seria

uma grande ameaça a saúde da população. Para se evitar tais riscos, sugeriu-se a utilização de produtos com corante e que os LAS não recebecem amostras tratadas com produtos sem corante. Além disso, sugeriu-se um rigoroso controle do destino dos lotes já tratados, por parte dos órgãos competentes.

2. De acordo com Wallen \& Seaman (1963), o fungo Phomopsis sp. tende a perder viabilidade durante o período de armazenagem, ocorrendo, ao 
mesmo tempo, uma elevação nos índices de germinação. Tal fato foi confirmado por Henning et al. (1981) que empregaram as sementes das cultivares Paraná, produzidas no sul de Minas Gerais, e Bossier, de Ponta Grossa. Após seis meses de armazenamento, o índice de sementes infectadas com Phomopsis sp. caiu para praticamente zero e, ao mesmo tempo, observou-se uma sensível elevação na porcentagem de germinação, principalmente na cultivar Paraná, onde o problema era quase que esclusivamente Phomopsis sp.

Diante do acima exposto, sugeriu-se que o tratamento das sementes, se necessario, fosse feito imediatamente antes da semeadura, pelo próprio agricultor.

\section{REFERÊNCIAS}

HENNING, A. A.; FRANÇA NETO, J. B. \& COSTA, N. P. Efeito da época de tratamento químico e/ou período de armazenagem sobre a qualidade fisiológica e sanitária das sementes de soja cv. Bossier e Paraná com altos índices de Phomopsis sp. In: CONGRESSO BRASILEIRO DE SEMENTES, 2. Recife, 1981. Resumo ... Brasília, ABRATES, 1981. p. 24.

HEPPERLY, P. R. \& SINCLAIR, J. B. Quality losses in Phomopsis infected soybean seeds. Phytopathology, 68 (12): 1684-7, 1978.

ILYAS, M. B.; DHINGRA, O. D.; ELLIS, M. A. \& SINCLAIR, J. B. Location of mycelium of Diaporthe phaseolorum var. sojae and Cercospora kikuchii in infected soybean seeds. Pl. Dis. Reptr., 59(1): 17-9, 1978.

RODRIGUES-MARCANO, A. \& SINCLAIR, J. B. Fruiting structures of Colletotrichum dematium var. truncata and Phomopsis sp. formed in soybean seeds. P1. Dis. Reptr., 62 (10): 873-6, 1978.

SCHNEIDER, R. W.; DHINGRA, O. D.; NICHOLSON, J. F. \& SINCLAIR, J. B. Colletotrichum truncatum borne within the seedcoat of soybean Phytopathology, 64 (1): 154-5, 1974.

SINCLAIR, J. B. \& SHURTLEFF, M. C. Compendium of soybean diseases. Minnesota, American Phytopathological Society, 1975. 69p.

WALLEN, V. R. \& SEAMAN, W. L. Seed infection of soybēan by Diaporthe phaseolorum and its influence on host development. Canadian Journal of Botany, 41: 13-21, 1963. 